\title{
Knowledge, attitudes, and perceptions of COVID-19 vaccine and refusal to receive COVID-19 vaccine among healthcare workers in northeastern Ethiopia
}

Metadel Adane ${ }^{1 \dagger}$, Ayechew Ademas ${ }^{1 * \dagger}$ and Helmut Kloos ${ }^{2}$

\begin{abstract}
Background: Major efforts are being made to control the spread and impacts of the coronavirus pandemic using vaccines. Ethiopia began on March 13, 2021, to vaccinate healthcare workers (HCWs) for COVID-19 with the AstraZeneca vaccine. However, willingness to be vaccinated depends to a large extent on factors beyond the availability of vaccines. This study aimed to determine the rate of intention to refuse COVID-19 vaccination and associated factors among HCWs in northeastern Ethiopia. northeastern, Ethiopia.

Method: An institution-based cross-sectional study was employed among $404 \mathrm{HCWs}$ in Dessie City, northeastern Ethiopia in May, 2021. Data were collected, checked, coded, entered into EpiData Version 4.6 and exported to Statistical Package of Social Sciences (SPSS) Version 25.0 for cleaning and analysis. The dependent variable was refuse to receive COVID-19 vaccination and the independent variables included socio-demographic factors, knowledge, attitudes and perceptions. A Binary logistic regression model was used to determine the association between vaccine refusal and the independent variables. From bivariate analysis, variables with $p$-values $<0.25$ were retained for multivariable analysis. From multivariable analysis, variables with adjusted odds ratio (AOR), $p$-values $<0.05$ at $95 \%$ confidence interval (CI) were declared as factors significantly associated with refusal to be vaccinated among HCWs in Dessie City, northeastern Ethiopia.
\end{abstract}

Results: The proportion of HCWs with overall good knowledge, good perception, and positive attitudes about COVID-19 vaccination were $62.5 \%, 60.5 \%$, and $52.3 \%$, respectively; $64.0 \%$ of the HCWs wanted to be vaccinated while $36.0 \%$ said that they would refuse to do so. Multivariable analysis identified negative attitudes (AOR: 3.057 ; 95\%Cl [1.860 - 5.026]) and poor perceptions (AOR: 4.73; 95\%Cl [2.911 - 7.684]) about COVID-19 vaccines were significantly associated with refusal to be vaccinated for COVID-19. Nearly half (46.9\%) of the HCWs stated that vaccines could worsen any pre-existing medical conditions and 39.5\% of them thought that vaccines could cause COVID-19 infections.

Conclusion: The willingness of HCWs to get vaccinated against COVID-19 was relatively high among HCWs. Negative attitudes and poor perceptions towards the anticipated COVID-19 vaccination were significant factors to refuse to

\footnotetext{
*Correspondence: aayechew19@gmail.com

${ }^{\dagger}$ Metadel Adane and Ayechew Ademas contributed equally to this work.

${ }^{1}$ Department of Environmental Health, College of Medicine and Health

Sciences, Wollo University, Dessie, Ethiopia

Full list of author information is available at the end of the article
}

(C) The Author(s) 2022. Open Access This article is licensed under a Creative Commons Attribution 4.0 International License, which permits use, sharing, adaptation, distribution and reproduction in any medium or format, as long as you give appropriate credit to the original author(s) and the source, provide a link to the Creative Commons licence, and indicate if changes were made. The images or other third party material in this article are included in the article's Creative Commons licence, unless indicated otherwise in a credit line to the material. If material is not included in the article's Creative Commons licence and your intended use is not permitted by statutory regulation or exceeds the permitted use, you will need to obtain permission directly from the copyright holder. To view a copy of this licence, visit http://creativecommons.org/licenses/by/4.0/. The Creative Commons Public Domain Dedication waiver (http://creativeco mmons.org/publicdomain/zero/1.0/) applies to the data made available in this article, unless otherwise stated in a credit line to the data. 
be vaccinated. Our findings may provide information for the management authorities and stakeholders to promote and improve attitudes, knowledge and perceptions towards COVID-19 vaccination uptake among HCWs.

Keywords: attitudes, COVID-19 vaccine, healthcare workers, knowledge, perceptions, vaccine refusal, Ethiopia

\section{Background}

COVID-19 infection rates are accelerating in Africa, including in Ethiopia. By October 24, 2021, Ethiopia had reported 362,088 COVID-19 cases and 6,347 deaths [1]. Many countries, including Ethiopia have implemented various strategies to control COVID-19, including declaring a state of emergency, issuing restrictions on mass gathering, enforcing stay-at-home orders, and promoting the use of personal protective equipment [2]. As part of the worldwide strategy, efforts have been made to develop and distribute vaccines. The COVAX program, backed by the World Health Organization (WHO) and other multilateral bodies, aims to supply 600 million doses to Africa, enough to vaccinate at least $20 \%$ of the population. However, by April 2021, only 18 million doses, representing $2 \%$ of all vaccine doses administered globally, had been administered by 41 African countries [3]. An additional 400 million doses of the Johnson \& Johnson vaccine are scheduled to be shipped to the African Union starting in the third quarter of 2021 [4]. The first large shipment (2.2 million doses) of the AstraZeneca vaccine was received by Ethiopia in early March 2021 through the COVAX program. The country expected to receive an additional 5.4 million doses by May 2021 [5]. In addition, the African Vaccine Acquisition Trust (AVAT) announced the first monthly shipment of 108,000 doses of Johnson \& Johnson vaccine to Ethiopia [6]. By April 2021, Ethiopia had administered only 430,000 doses of COVID vaccines, covering $0.2 \%$ of the country's population with 2-shot vaccinations [7], but expected to cover $20 \%$ of the population by the end of 2021 [5, 8]. As of October 26, 2021, while more than 3.84 billion people worldwide had received one dose of a COVID-19 vaccine (equal to about $50 \%$ of the world population), 24 African countries had vaccinated less than $3 \%$ of their populations and only $0.9 \%$ of Ethiopia's population had been fully vaccinated [9].

Ethiopia began on March 13, 2021, to vaccinate HCWs for COVID-19 with the AstraZeneca vaccine. Healthcare workers include medical doctors, laboratory technicians, nurses, midwives, pharmacists, radiographers, anesthesiologists, public health and environmental health officers, any any other professionals including non-medical auxiliary staff who work in a healthcare facility. Non-medical auxiliary staff are other than health professionals such as financial workers, human resource workers, janitors, card room and documentation workers, porters, guardians and others.

Elderly people above the age of 60 and those above 50 years who have chronic diseases are also prioritized by the Ethiopian Ministry of Health. The launch of the vaccine program was attended by the WHO country representative Boueri Hama Sambo, who urged "communities and community leaders to build trust" as well as "demand for the vaccine" and to "promptly address "misinformation" [8]. During that event, one health worker was not convinced, saying "I don't believe in this vaccine. The virus is a sign of God's wrath upon us, so I prefer to pray" [8]. Negative attitudes and mistrust towards COVID-19 vaccines are major barriers to increasing vaccine coverage worldwide [10].

Despite the scarcity of COVID-19 vaccines in Africa, several countries including Sierra Leone and Malawi have discarded large numbers of vaccines doses that expired before they were used due to low demand in the population, a situation also anticipated in Uganda [11]. In addition to the low accessibility of COVID-19 vaccines and hesitancy to be vaccinated for COVID-19, a preference for traditional medicines may constitute another barrier to vaccine acceptance in African countries, including Ethiopia. Indigenous medicines have been used to treat COVID-19 in Tanzania and Madagascar without meeting safety and efficacy standards [12]. The use of these plant products to treat COVID-19 carries safety risks and may hinder use of scientifically proven COVID19 vaccinations. A study in Nepal revealed that the use of medicinal plants has increased since the outbreak of the COVID-19 pandemic [13]. The use of traditional medicine for COVID-19 and its impact on vaccination rates has not been investigated in Ethiopia. However, it is known that some plant extracts have traditionally been used to treat influenza [14], and people may prefer using them rather than accepting COVID-19 vaccines in the absence of diagnostic tests.

Willingness to receive a COVID-19 vaccine is a challenge in many countries [15]. COVID-19 vaccine acceptance rates in the general population were highest in Vietnam (98\%), India (91\%), China (91\%), Denmark (87\%), and South Korea (87\%) and lowest in Serbia (38\%), Croatia (41\%), France (44\%), Lebanon (44\%), and Paraguay (51\%) [16]. High hesitancy rates were also reported worldwide among HCWs, who play a central role in reducing the burden of the pandemic through their role 
in modeling preventive behavior and administering vaccinations. A review of 35 studies revealed that vaccination hesitancy rates varied from $4.3 \%$ to $72 \%$ worldwide [17]. Major concerns of health workers were vaccine safety, efficacy, and potential side effects. Higher socioeconomic status, directly working with patients, perceived risk and fear of COVID-19, and a history of influenza vaccination were associated with higher vaccine uptake [17].

Reluctance of HCWs to accept COVID-19 vaccination may not only increase the risk of virus transmission to their patients but also reduce the likelihood that HCWs will encourage patients to be vaccinated [17]. There is no documented evidence regarding attitudes and perceptions of Ethiopian health workers towards COVID-19 vaccination. This study examines knowledge, attitudes, perceptions towards the COVID-19 vaccine, level of refusal and associated factors of COVID-19 vaccination among HCWs in Dessie City, Ethiopia.

\section{Methods}

\section{Study design, period and setting}

This institution-based cross-sectional study was conducted in Dessie City in May, 2021. Dessie is the capital of South Wollo Zone, located about $400 \mathrm{~km}$ from Addis Ababa. The city is located at an altitude of 2,470 to 2,550 meters. According to Dessie City administration health office, the city has 8 health centers, 2 government hospitals, 3 private hospitals and 15 clinics.

\section{Source population, inclusion and exclusion criteria}

The source population for the study included all HCWs in Dessie City. The study population was all HCWs in the selected health facilities. All HCWs present at the selected health institutions during the survey were included in the study. Those who were absent (on sick leave, annual leave, or maternity leave) were excluded and not considered in sampling procedure (interval calculation) based on payroll lists.

\section{Sample size determination and sampling procedure}

A total of 404 study participants were identified by using the single population proportion formula and considering the following assumptions:

$$
n=\frac{\left(z_{a / 2}\right)^{2} * p(1-p)}{d^{2}}
$$

where: $\boldsymbol{n}$ : is the minimum sample size required, $\boldsymbol{Z}_{\boldsymbol{\alpha} / 2}$ is the standard normal variable at (1- $\alpha) \%$ confidence level ( $\alpha$ is 0.05 with $95 \% \mathrm{CI}, \mathrm{Z}_{\alpha / 2}=1.96$ ), $P$ is an estimate of the attitude towards COVID-19 vaccine (50\%) and $\boldsymbol{d}$ is the margin of error (5\%). Based on these assumptions, 384 individuals were estimated. Then $5 \%$ of the sample size contingency was added to minimize errors arising from the likelihood of non-compliance, giving a final sample size of 404.

To select study subjects, 11 health institutions (2 government hospitals, 2 private hospitals, 4 health centers, and 3 private clinics) were randomly selected. For the selected healthcare facilities, study subjects' proportional allocation was made based on their number regardless of the profession. Then each institution's payroll for all professions and systematic random sampling was used to identify study participants. The first participant was selected by the simple lottery method. Professions represented in the study included medical doctors, laboratory technicians, nurses, midwives, ophthalmologists, pharmacists, public health officers, radiographers, environmental health specialists, anesthesiologists, porters, medical record workers, administrative staff, cleaners, laundry workers, and guards.

\section{Outcome measurement and explanatory variables}

The independent variables were socio-demographic factors, knowledge, attitudes, and perceptions and the dependent variable was refusalof to receive COVID-19 vaccination. To compute the three outcome variables of knowledge (good or poor), attitude (positive or negative), and perception (good or poor), we used the mean score of responses to 9 questions about knowledge and perceptions and 8 questions about attitudes. A score of $\mathbf{1}$ was assigned for poor knowledge, negative attitude and poor perception and a score of $\mathbf{2}$ for good knowledge, positive attitude and good perception. Scores above the mean value for each category were considered as good knowledge, positive attitude, and good perception. In addition, refusal to receive the COVID-19 vaccine was correlated as an outcome variable with socio-demographic, knowledge, attitude, and perception as independent variables.

\section{Data collection and quality assurance}

The data were collected using a structured questionnaire adapted from relevant literature. Data were collected both through a self-administered questionnaire and interviews with selected professionals. Ten nurses with BSc degrees and 5 environmental health professionals with BSc degrees were employed as data collectors and supervisors. To ensure the acquisition of reliable data, both data collectors and supervisors were trained by the principal investigator for one day on the objectives of the study, the content of the questionnaire, ethical issues, and methods of data collection. We also pre-tested the questionnaire on $5 \%$ of the sample size among HCWs in nearby Haik Town before actual data collection and made adjustments in the questionnaire where necessary. The collected data were checked daily by the supervisors 
for completeness. To ensure accurate and reliable data, the reliability of the questionnaire was assessed using the Cronbach alpha test, giving values of $0.82,0.79$, and 0.87 for knowledge, attitude and perception questions, respectively. We also assessed the validity of this questionnaire by recruiting experts to evaluate the content of the questionnaire using face validity, resulting in the experts agreeing that the test was a valid measure of the concept being measured. This means that they evaluated whether each of the measured items matched any given domain of the concept.

\section{Data management and statistical analysis}

The collected data were checked, coded, and entered into EpiData Version 4.6 and exported to Statistical Package for Social Sciences (SPSS) Version 25.0 for data cleaning and analysis. Descriptive statistics, such as frequency distribution (n) and proportions (\%) were computed. We ran a logistic regression analysis using socio-demographic, knowledge, attitudes and perceptions as independent variables and refusal of vaccination as the dependent variable. First, bivariate logistic regression analysis (crude odds ratio [COR] at 95\% confidence interval [CI]) was performed and then variables with $p<0.25$ were retained for multivariablelogistic regression analysis.

From the multivariable analysis, variables with a significance level of $p<0.05$ with adjusted odds ratio (AOR) at $95 \% \mathrm{CI}$ were taken as statistically significant factors that were independently associated with the refusal of vaccination.

Model goodness of fit was checked using the Hosmer and Lemeshow test; $P$-values greater than 0.05 showed a value of 0.27 , indicating the model was fit. Multi-collinearity between independent variables was also checked using the standard error of the coefficient of the model with a cut off value of 2. A maximum standard error value of 0.683 was reported from our model indicating the absence of multi-collinearity between independent variables.

\section{Results}

\section{Socio-demographic characteristics of respondents}

Of the 404 study participant HCWs, the response rate was $97.0 \%$. The mean age of the respondents was 34.37 years (standard deviation $[\mathrm{SD}]= \pm 7.785$ ) and 198 were male (50.5\%) and 194 female (49.5\%). The study participants included 34 (8.7\%) medical doctors, 46 (11.7\%) laboratory technicians, 130 (33.2\%) nurses and midwives, 50 (12.7\%) pharmacists, 18 (4.6\%) radiographers, 21 (5.4\%) anesthesiologists, 36 (9.2\%) public health officers and environmental health officers, and 57 (14.5\%) non-medical auxiliary staff. The majority were university degree holders 257 (65.6\%), 315 (80.4\%) did not have health insurance, and more than one-third 157(40.1\%) had received training or orientation about COVID-19 vaccination. The great majority $(91.3 \%)$ of respondents did not have any chronic condition while $3.6 \%$ had hypertension, $2.3 \%$ asthma, $1.8 \%$ diabetes, and $0.5 \%$ each had HIV/AIDS and/or kidney disease (Table 1).

\section{HCWs knowledge about COVID-19 vaccines}

The mean score of the knowledge was 14.97, with a standard deviation of 1.881 . The overall good knowledge rate of the HCWs about COVID-19 and its vaccine was $62.5 \%$ with 95\% CI (57.4-66.8\%). Of those who had good knowledge of COVID-19 and its vaccine, 171 (69.79\%) were planning to be vaccinated as soon as a vaccine becomes available. One hundred twenty-eight (64.65\%) males and $117(60.3 \%)$ females had good knowledge whereas 70 (35.35\%) males and 77 (39.69\%) females had poor knowledge about COVID-19 and its vaccines. Similarly, 20 (58.8\%) doctors, 31 (67.4\%) laboratory technicians, 84 (64.6\%) nurses, and midwives and 31 (54.38\%) non-medical axillary staff had good knowledge. Among those who had a chronic disease, 22 (64.7\%) had good knowledge. The majority $(340,86.7 \%)$ responded that COVID-19 is a serious disease and $329(83.9 \%)$ stated that it could result in many health complications. One hundred fifty (38.3\%) HCWs considered the differences in the effectiveness among the Pfizer, Moderna, and Astra Zeneca COVID19 vaccines to be large. More than three-quarters (77.6\%) of the HCWs considered the major mode of COVID-19 transmission to be touching contaminated surfaces and touching one's eyes, nose, and mouth, followed by shaking hands, hugging, and kissing (70.4\%) and inhaling the virus (69.9\%) (Table 2).

COVID-19 disease was associated with untreated infections. Two hundred thirteen $(54.3 \%)$ of the respondents stated that it could result in pneumonia and 279 (71.2\%) in respiratory failure (Fig. 1).

\section{HCWs attitudes towards COVID-19 vaccines}

The mean score of attitudes was 13.31, with a standard deviation of 1.529 . The overall positive attitude rate about the COVID-19 vaccine was $52.3 \%$ with $95 \%$ CI $(47.7$ - 57.4\%). Of those who had a positive attitude towards the COVID-19 vaccine, 189 (79.75\%) were planning to get vaccinated when a vaccine becomes available. One hundred-nine (55.05\%) males and 96 (49.5\%), females had a positive attitude while $89(44.95 \%)$ of males and 98 (50.5\%) of females had a negative attitude towards COVID-19 vaccines.

Fifteen $(44.12 \%)$ of the medical doctors, 30 (65.23\%) laboratory technicians, 66 (50.77\%) nurses and midwives, and $32(56.14 \%)$ non-medical auxiliary staff had a positive attitude towards the COVID-19 vaccine. Of those 
Table 1 Socio-demographic characteristics among healthcare workers in Dessie City, Ethiopia, May 2021

\begin{tabular}{|c|c|c|}
\hline Questions & Frequency $(n)$ & Percentage (\%) \\
\hline \multicolumn{3}{|l|}{ Sex } \\
\hline Male & 198 & 50.5 \\
\hline Female & 194 & 49.5 \\
\hline \multicolumn{3}{|l|}{ Age (years) } \\
\hline 20-30 & 157 & 40.1 \\
\hline $31-40$ & 156 & 39.8 \\
\hline $41-50$ & 16 & 16.8 \\
\hline $51-60$ & 13 & 3.3 \\
\hline \multicolumn{3}{|l|}{ Education status } \\
\hline Primary level & 7 & 1.8 \\
\hline Secondary level & 9 & 2.3 \\
\hline Diploma & 119 & 30.3 \\
\hline University degree & 257 & 65.6 \\
\hline \multicolumn{3}{|l|}{ Profession } \\
\hline Medical doctor & 34 & 8.7 \\
\hline Laboratory technician & 46 & 11.7 \\
\hline Nurse and midwive & 130 & 33.2 \\
\hline Pharmacist & 50 & 12.7 \\
\hline Radiographer & 18 & 4.6 \\
\hline Anesthesiologist & 21 & 5.4 \\
\hline Public health officer & 36 & 9.2 \\
\hline Nonmedical auxiliary staff & 57 & 14.5 \\
\hline \multicolumn{3}{|l|}{ Religion } \\
\hline Orthodox Christian & 213 & 54.3 \\
\hline Protestant & 29 & 7.4 \\
\hline Muslim & 150 & 38.3 \\
\hline \multicolumn{3}{|l|}{ Marital status } \\
\hline Single & 144 & 36.7 \\
\hline Married & 214 & 54.6 \\
\hline Divorced, widowed or separated & 34 & 8.6 \\
\hline \multicolumn{3}{|l|}{ Where did you grow up? } \\
\hline Rural & 151 & 38.5 \\
\hline Semi-urban & 77 & 19.6 \\
\hline Urban & 164 & 41.8 \\
\hline \multicolumn{3}{|l|}{ Household size (persons) } \\
\hline$\leq 5$ & 277 & 70.7 \\
\hline$>5$ & 115 & 29.3 \\
\hline \multicolumn{3}{|l|}{ Years worked in a healthcare facility } \\
\hline 10 or less & 306 & 78.1 \\
\hline$>10$ & 86 & 21.9 \\
\hline \multicolumn{3}{|l|}{ Do you have health insurance? } \\
\hline No & 315 & 80.4 \\
\hline Yes & 77 & 19.6 \\
\hline \multicolumn{3}{|c|}{ Has anyone in your family or of your colleagues or friends had COVID-19? } \\
\hline Yes & 129 & 32.9 \\
\hline No & 263 & 67.1 \\
\hline \multicolumn{3}{|l|}{ Have you been tested for COVID-19? } \\
\hline Yes & 132 & 33.7 \\
\hline No & 260 & 66.3 \\
\hline
\end{tabular}


Table 1 (continued)

\begin{tabular}{|c|c|c|}
\hline Questions & Frequency $(n)$ & Percentage (\%) \\
\hline \multicolumn{3}{|c|}{ If "yes", were you positive? ( $N=132)$} \\
\hline Yes & 25 & 18.9 \\
\hline No & 107 & 81.1 \\
\hline \multicolumn{3}{|c|}{ Do you have any chronic diseases? } \\
\hline Yes & 34 & 8.7 \\
\hline No & 358 & 91.3 \\
\hline \multicolumn{3}{|l|}{ Smoking status } \\
\hline Current smoker & 12 & 3.1 \\
\hline Ex-smoker & 33 & 8.4 \\
\hline Never smoked & 347 & 88.5 \\
\hline \multicolumn{3}{|c|}{ Have you received any training or orientation about COVID-19 vaccination? } \\
\hline Yes & 157 & 40.1 \\
\hline No & 235 & 59.9 \\
\hline \multicolumn{3}{|c|}{ How many times have you received training/orientation? } \\
\hline Once & 116 & 29.6 \\
\hline More than once & 41 & 10.4 \\
\hline \multicolumn{3}{|c|}{ Source of information about COVID-19 vaccine (multiple responses possible) } \\
\hline Television & 326 & 83.2 \\
\hline Internet & 263 & 67.1 \\
\hline Radio & 230 & 58.7 \\
\hline Scientific literature & 159 & 40.6 \\
\hline Relatives and friends & 127 & 32.4 \\
\hline
\end{tabular}

who had a chronic disease, 19 (55.9\%) had a positive attitude towards COVID-19 vaccines. Two-fifths (40.6\%) of the HCWs were confident that the Ministry of Health can control COVID-19 in Ethiopia but $55.4 \%$ of them expressed a general mistrust/uncertainty about the effectiveness of COVID-19 vaccines (Table 3 ).

\section{Perceptions of HCWs about COVID-19 vaccines}

The mean score of perceptions was 14.66, with a standard deviation of 1.866. The overall rate of good perception about the COVID-19 vaccine was $60.5 \%$ with $95 \%$ CI (55.6-65.3\%). Of those who had a good perception about COVID-19 vaccine, only 189 (79.75\%) were planning to be vaccinated. Nearly two-thirds $125(63.13 \%)$ of the male and $112(57.73 \%)$ of the female HCWs had a good perception whereas $73(36.87 \%)$ of the males and 82 $(42.3 \%)$ of the females had a poor perception of COVID19 vaccines.

Nineteen (55.9\%) doctors, 32 (69.57\%) laboratory technicians, $86(66.15 \%)$ nurses and midwives, 24 (48\%) pharmacists, and 33 (57.9\%) non-medical auxiliary staff had a good perception about COVID-19 vaccines. One hundred twenty-six $(59.15 \%)$ of the Orthodox Christians, 16(55.17\%) of the Protestants, and 95(63.3\%) Muslims had a good perception about COVID-19 vaccines. Eighty-nine (58.9\%), 44 (57.14\%) and 104 (63.41\%) HCWs who grew up in rural, semi-urban and urban areas, respectively, had a good perception of the COVID-19 vaccines. Among those who had a chronic disease, 23 (67.65\%) had good perceptions.

Three-quarters $(292,74.5 \%)$ of the HCWs considered themselves to be at high risk of becoming infected with COVID-19 and 39.5\% of them thought that they could get infected with COVID-19 through vaccination. Of these, $56(14.3 \%)$ in the 20-30 age group, 67 (17.1\%) aged 31-40, $26(6.6 \%)$ aged $41-50$ and $6(1.5 \%)$ in the 51-60 age group linked vaccines to COVID-19 infection. With regard to educational level, 6 (1.5\%) HCWs with secondary education and below (grades 12 and below), 49 (12.5\%) with diplomas, and 100 (25.5\%) with university degrees associated vaccines with infection. Among the different occupational categories, 16 (4.1\%) medical doctor, 21 (5.4\%) medical laboratory technician, $50(12.6 \%)$ nurse and midwive, 18 (4.6\%) pharmacist, 15 (3.8\%) public health officer, $9(2.3 \%)$ anesthesiologist, 10 (2.6\%) radiographer and $16(4.1 \%)$ non-medical auxiliary staff believed that they could get infected with COVID-19 through vaccination. Similarly, nearly half $(184,46.9 \%)$ of the HCWs thought that vaccines could worsen any pre-existing medical conditions. On the other hand, 173 (44.1\%) of the respondents thought that it may not be possible to reduce the incidence of COVID-19 without vaccination (Table 4). 
Table 2 Knowledge about COVID-19 and COVID-19 vaccines among healthcare workers in Dessie City, Ethiopia, May 2021

\begin{tabular}{|c|c|c|}
\hline Questions & Frequency $(n)$ & Percentage (\%) \\
\hline \multicolumn{3}{|l|}{ Is COVID-19 a serious disease? * } \\
\hline Yes & 340 & 86.7 \\
\hline No & 29 & 7.4 \\
\hline I don't know ${ }^{\delta}$ & 23 & 5.9 \\
\hline \multicolumn{3}{|l|}{ Do you know that COVID-19 can result in complications? * } \\
\hline Yes & 329 & 83.9 \\
\hline No & 63 & 16.1 \\
\hline \multicolumn{3}{|l|}{ Can vaccines effectively prevent COVID-19? * } \\
\hline & Yes 161 & 41.1 \\
\hline No & 112 & 28.6 \\
\hline I don't know $\delta$ & 119 & 30.4 \\
\hline \multicolumn{3}{|l|}{ Can COVID-19 be acquired after full vaccination? * } \\
\hline Yes & 132 & 33.7 \\
\hline No & 111 & 28.3 \\
\hline I don't know ${ }^{\delta}$ & 149 & 38.0 \\
\hline \multicolumn{3}{|c|}{ Do you know where you can be vaccinated when a COVID-19 vaccine becomes available? * } \\
\hline Yes & 255 & 65.1 \\
\hline No & 137 & 34.9 \\
\hline \multicolumn{3}{|c|}{ * Are there large differences in the effectiveness of the Pfizer, Moderna, and Astra Zeneca COVID-19 vaccines? } \\
\hline Yes & 150 & 38.3 \\
\hline No & 242 & 61.7 \\
\hline \multicolumn{3}{|c|}{ Does the effectiveness of the major COVID-19 vaccines vary between about $50 \%$ and $95 \% ?(N=150)$} \\
\hline Yes & 103 & 68.7 \\
\hline No & 17 & 13.3 \\
\hline I don't know & 30 & 20.0 \\
\hline \multicolumn{3}{|l|}{ Do COVID-19 vaccines have side effects? * } \\
\hline Yes & 279 & 71.2 \\
\hline No & 48 & 12.2 \\
\hline I don't know $\delta$ & 65 & 16.6 \\
\hline \multicolumn{3}{|c|}{$\begin{array}{l}\text { Are older people and chronic disease patients most likely to experience severe illness and death from } \\
\text { COVID-19 infection?* }\end{array}$} \\
\hline Yes & 354 & 90.3 \\
\hline No & 38 & 9.7 \\
\hline \multicolumn{3}{|c|}{ Are HCWs more vulnerable to COVID-19 infection than the general public? * } \\
\hline Yes & 340 & 86.7 \\
\hline No & 25 & 6.4 \\
\hline I don't know $\delta$ & 27 & 6.9 \\
\hline \multicolumn{3}{|c|}{ Knowledge of HCWs about the mode of transmission of COVID-19 (multiple responses possible) } \\
\hline Poor hygiene & 218 & 55.6 \\
\hline Inhalation of the virus & 274 & 69.9 \\
\hline Touching contaminated surfaces, eyes, nose or mouth & 304 & 77.6 \\
\hline Shaking hands, hugging, and kissing & 276 & 70.4 \\
\hline
\end{tabular}

*These questions are used to compute the overall score of knowledge

"The third choice "I don't know" in some questions was included in the "No" category for the analysis

Nearly two-thirds 251 (64.0\%) with 95\%CI (59.4$68.6 \%)$ of the HCWs were planning to be vaccinated and 141 (36.0\%) with 95\% CI (31.4-40.6\%) refused to be vaccinated for COVID-19 (Table 3). Bivariate analysis identified the following factors in the refusal to be vaccinated: absence of COVID-19 in the family or among 


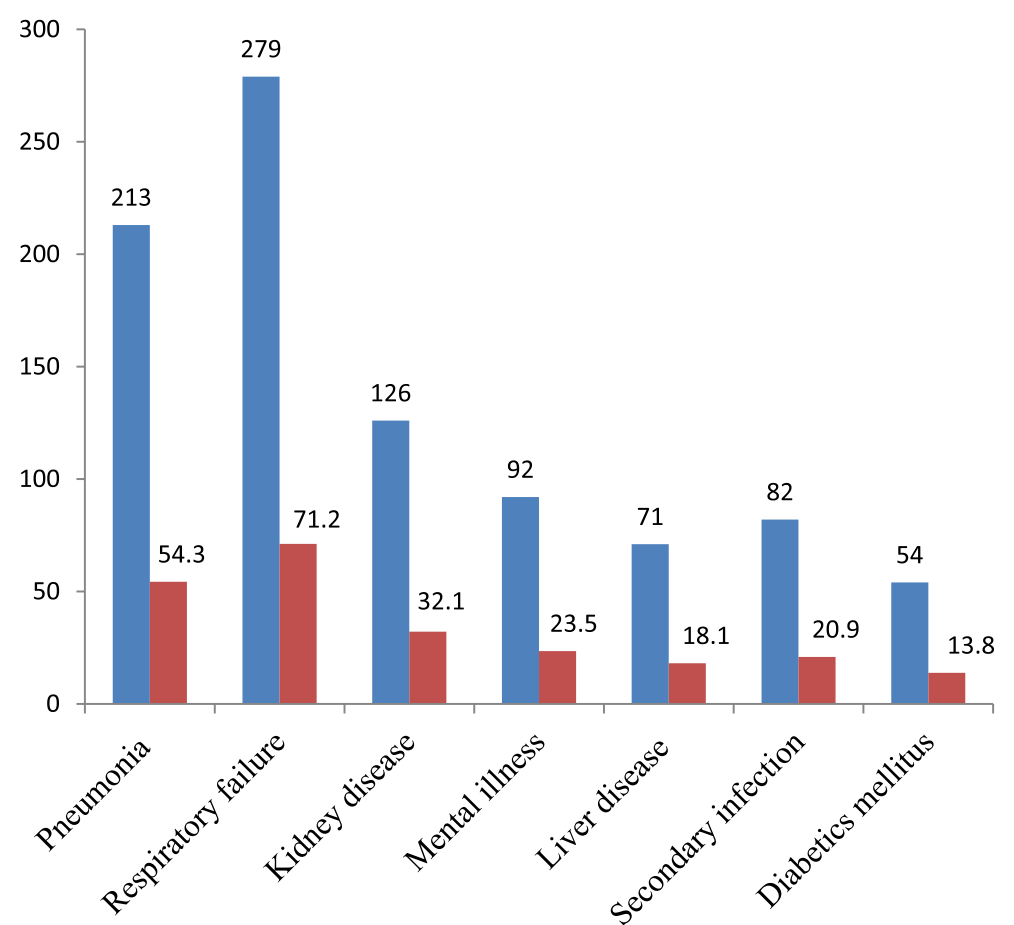

Fig. 1 Respondents' knowledge about complication of COVID-19

colleagues and friends, failure to be tested for COVID-19, failure to obtain training or orientation about COVID-19 vaccination, negative attitude, and poor knowledge and perception (Table 5).

\section{Proportion of refusal to be vaccinated for COVID-19}

One hundred forty-one (36.0\%, 95\% CI [31.4-40.6\%]) refused to be vaccinated for COVID-19 when vaccines become available and 251 (64.0\%, 95\% CI [59.4- 68.6\%]) said that they wanted to be vaccinated.

\section{Factors associated with refusal to be vaccinated}

In multivariable analysis, refusal to be vaccinated for COVID-19 vaccine was significantly associated with a negative attitude (AOR: 3.06; 95\% CI [1.86-5.03]) and poor perception (AOR: 4.73; 95\% CI [2.91-7.68]). HCWs who had negative attitude about COVID-19 vaccines were 3.06 times refused to be vaccinated compared to those who had positive attitude towards COVID-19 vaccines. Furthermore, HCWs who had poor perception about COVID-19 vaccines were 4.73 times refused to be vaccinated compared to those who had good perception towards COVID-19 vaccines. However, being nurses and midwives (AOR: 0.38; 95\% CI [0.15-0.97]) was significantly associated with to be vaccinated for COVID19 vaccine compared to other HCWs. Also, most pharmacists refused to be vaccinated but this association was not statistically significant (Table 6).

\section{Discussion}

On-going efforts are been made to end the COVID-19 pandemic. Various COVID-19 vaccines have been distributed in many countries, including Ethiopia. The overall good knowledge, good perception, and positive attitude rates of the HCWs about COVID-19 vaccines were $62.5 \%, 60.5 \%$, and $52.3 \%$, respectively.

In our study, $64.0 \%$ of the HCWs planned to be vaccinated and $36.0 \%$ refused to do so. A similar vaccine acceptance rate was reported by a study in Iraq (61.7\%) [18], which was higher than in two studies in the USA, where more than half of all HCWs were undecided and delayed the decision to be vaccinated $[19,20]$. Low acceptance rates were also reported among healthcare workers in Ghana (39.3\%) [21]), the Democratic Republic of Congo (27.7\%) [22]), Egypt (21\%) [23]), and Nepal (38.3\%) [24]). Studies in Nigeria and Saudi Arabia reported intended vaccine uptake rates of 50.2\% [25] and $50.52 \%$, respectively [26]. Low rates may be due to earlier study dates (when prospects of the vaccine rollout were uncertain), HCWs limited knowledge about vaccines, lack of trust in government management capacity, and concerns about vaccine safety. 
Table 3 Attitudes towards COVID-19 vaccines among healthcare workers in Dessie City, Ethiopia, May 2021

\begin{tabular}{|c|c|c|}
\hline Questions & Frequency $(n)$ & Percentage (\%) \\
\hline \multicolumn{3}{|c|}{ Are you confident that the Ministry of Health can control COVID-19 in Ethiopia? * } \\
\hline Yes & 159 & 40.6 \\
\hline No & 233 & 59.4 \\
\hline \multicolumn{3}{|c|}{ Do you have general mistrust/uncertainty about COVID-19 vaccine effectiveness? * } \\
\hline Yes & 217 & 55.4 \\
\hline No & 175 & 44.6 \\
\hline \multicolumn{3}{|l|}{ Do you fear COVID-19 vaccines? * } \\
\hline Yes & 221 & 56.4 \\
\hline No & 171 & 43.6 \\
\hline \multicolumn{3}{|c|}{ Reasons for fearing COVID-19 vaccines $(N=221)$} \\
\hline Infertility & 55 & 24.9 \\
\hline Severe allergic reactions & 72 & 32.6 \\
\hline Unknown long-term effects & 94 & 42.5 \\
\hline \multicolumn{3}{|c|}{ Are you planning to be vaccinated for COVID-19? } \\
\hline Yes & 251 & 64.0 \\
\hline No & 141 & 36.0 \\
\hline \multicolumn{3}{|c|}{ Do you refuse to get vaccinated because only God/Allah can prevent COVID-19?* } \\
\hline Yes & 137 & 34.9 \\
\hline No & 255 & 65.1 \\
\hline \multicolumn{3}{|c|}{ What alternative preventive measures did you use to prevent COVID-19 } \\
\hline Traditional medicine & 15 & 3.8 \\
\hline Praying & 48 & 12.2 \\
\hline Physical exercise & 43 & 11.0 \\
\hline \multicolumn{3}{|c|}{ Should people with chronic and severe diseases get priority for COVID-19 vaccination? * } \\
\hline Yes & 341 & 87.0 \\
\hline No & 51 & 13.0 \\
\hline \multicolumn{3}{|c|}{ Should HCWs get priority in COVID-19 vaccination? * } \\
\hline Yes & 340 & 86.7 \\
\hline No & 52 & 13.3 \\
\hline \multicolumn{3}{|c|}{ Should all HCWs be vaccinated to protect the public? * } \\
\hline Yes & 276 & 70.4 \\
\hline No & 62 & 15.8 \\
\hline I don't know $\delta$ & 54 & 13.8 \\
\hline \multicolumn{3}{|c|}{ To protect the public, HCWs should follow government guidelines about vaccines * } \\
\hline Agree & 322 & 82.1 \\
\hline Disagree & 70 & 17.9 \\
\hline
\end{tabular}

*These questions are used to compute the overall score of attitude

¿ To compute the overall score of Attitude, the third choice "I do not know" in some questions were included in the "No" category for analysis

Some of the highest vaccine acceptance rates (above 95\%) were reported from South and Southeast Asia, where HCWs were willing to be vaccinated because as they perceived the pandemic to be severe, considered the vaccines to be safe, experienced few financial constraints and little stigmatization of being vaccinated, and trusted the health authorities [27]. Studies in China and Vietnam reported intended vaccine uptakes of $76.63 \%$ [28] and $76.10 \%$, respectively [29], slightly higher than our findings. These high rates were associated with good knowledge regarding the severity of COVID-19, HCWs' trust in the vaccines, and earlier study dates than in our study.

In this study, high rates of not intending to be vaccinated when vaccines become available were associated with negative attitude and low perception about COVID19 vaccine. Our study also showed that being a nurse and midwife was significantly associated with acceptance to be vaccinated for COVID-19. Consistent with our findings, a study in India found vaccine acceptance 
Table 4 Perception towards COVID-19 vaccine among healthcare workers in Dessie City, Ethiopia, May 2021

\begin{tabular}{|c|c|c|}
\hline Questions & Frequency $(n)$ & Percentage (\%) \\
\hline \multicolumn{3}{|c|}{ Do you think you are at high risk of becoming infected with COVID-19? } \\
\hline Yes & 292 & 74.5 \\
\hline No & 73 & 18.6 \\
\hline I don't know $\delta$ & 27 & 6.9 \\
\hline \multicolumn{3}{|c|}{ Do you think that you could get infected with COVID-19 through vaccination? } \\
\hline Yes & 155 & 39.5 \\
\hline No & 165 & 42.1 \\
\hline I don't know ${ }^{\delta}$ & 72 & 18.4 \\
\hline \multicolumn{3}{|c|}{ Is it possible to reduce and control the incidence of covid- 19 without vaccination? } \\
\hline Yes & 173 & 44.1 \\
\hline No & 174 & 44.4 \\
\hline I don't know ${ }^{\delta}$ & 45 & 11.5 \\
\hline \multicolumn{3}{|c|}{ Do most of my colleagues appear to think that getting vaccinated is a good idea? } \\
\hline Yes & 272 & 69.4 \\
\hline No & 72 & 18.4 \\
\hline I don't know ${ }^{\delta}$ & 48 & 12.2 \\
\hline \multicolumn{3}{|c|}{$\begin{array}{l}\text { Is getting yourself vaccinated for COVID-19 a good way to protect your family and other } \\
\text { people against infection? }\end{array}$} \\
\hline Yes & 274 & 69.9 \\
\hline No & 83 & 21.2 \\
\hline I don't know $\delta$ & 35 & 8.9 \\
\hline \multicolumn{3}{|c|}{ My family and friends think that getting vaccinated for COVID-19 is a good idea } \\
\hline Agree & 285 & 72.7 \\
\hline Disagree & 60 & 15.3 \\
\hline Neutral ${ }^{\delta}$ & 47 & 12.0 \\
\hline \multicolumn{3}{|c|}{ Do you think that the COVID-19 vaccine can worsen any health conditions you have? } \\
\hline Yes & 184 & 46.9 \\
\hline No & 140 & 35.7 \\
\hline I don't know $\delta$ & 68 & 17.4 \\
\hline \multicolumn{3}{|c|}{ Do you believe that you can get proper medical care if you contract COVID-19? } \\
\hline Yes & 197 & 50.3 \\
\hline No & 131 & 33.4 \\
\hline I don't know ${ }^{\delta}$ & 64 & 16.3 \\
\hline \multicolumn{3}{|c|}{$\begin{array}{l}\text { Do you think that the development of COVID-19 vaccines was properly carried out to make } \\
\text { them safe? }\end{array}$} \\
\hline Yes & 282 & 71.9 \\
\hline No & 110 & 28.1 \\
\hline
\end{tabular}

"These questions are included to compute the overall score of perception, the third choice "I don't know/ neutral" in some questions was categorized into the "No/disagree" category for the analysis

to be highest among nurses [30]. However, in a study in the Democratic Republic of the Congo, the highest acceptance rates among HCWs were reported for medical doctors [22] and in Debre Tabor Hospital in northern Ethiopia, nurses had the lowest acceptance rates [31].

Our findings corroborate a study from the Democratic Republic of the Congo that reported that having a positive attitude towards COVID-19 vaccines was significantly associated with the willingness to receive a vaccine [22]. A study among HCWs of an inner-city hospital in New York [32] reported similar results. A study in Libya indicated that having a family member or friend infected with COVID-19 was positively associated with the likelihood of vaccine acceptance [33]. A community-based study in Wolaita Zone, Ethiopia, showed that family members and friends who had been 
Table 5 Bivariate analysis of factors associated with refusal of COVID-19 vaccine among healthcare workers in Dessie City, Ethiopia, May 2021

\begin{tabular}{ll}
\hline Variables & $\begin{array}{l}\text { Refusal of } \\
\text { vaccination }\end{array}$ \\
\cline { 2 - 3 } & Yes NoR $(95 \% \mathrm{Cl})$ \\
\hline
\end{tabular}

Sex
Male
Fema
Age (years)
$20-30$
$31-40$
$41-50$
$51-60$

Educational status *

Secondary or below level

Diploma

University degree

Religion *

Christian

Muslim

Marital status

Currently single

Married

Place of residence where you grew up

Rural

Semi-urban

Urban

Household size (persons)

Five or less

More than five

Duration of work as HCW

10 years or less

$>10$ years

Have health insurance

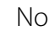

Yes

Anyone in your family or colleague or friend had COVID-19*

No

Yes

Tested for COVID-19 *

No

Yes

Have a chronic disease

No

Yes

Smoking status

Currently smoke

Ex-smoker

Never smoked

$\begin{array}{lll}68 & 130 & 0.87(0.57-1.31) \\ 73 & 121 & \operatorname{Ref} \\ & & \\ 59 & 98 & 1.36(0.39-4.59) \\ 57 & 99 & 1.29(0.38-4.39) \\ 21 & 45 & 1.05(0.29-3.80) \\ 4 & 9 & \operatorname{Ref}\end{array}$

$4 \quad 12 \quad 0.65(0.20-2.08)$

$50 \quad 69 \quad 1.42(0.91-2.21)$

$87 \quad 170 \quad$ Ref

$96 \quad 146 \quad 1.53(0.99-2.37)$

$45 \quad 105 \quad$ Ref

$67 \quad 111 \quad 1.14(0.76-1.73)$

$74 \quad 140 \quad$ Ref

$58 \quad 93 \quad 1.24(0.78-1.96)$

$28 \quad 49 \quad 1.13(0.64-1.99)$

$55 \quad 109$ Ref

$103 \quad 174 \quad 1.19(0.76-1.89)$

$38 \quad 77 \quad$ Ref

$114192 \quad 1.29(0.78-2.16)$

$27 \quad 59 \quad$ Ref

$117 \quad 198 \quad 1.31(0.77-2.23)$

2453 Ref

$107 \quad 156 \quad 1.92(1.21-3.04)$

$34 \quad 95 \quad$ Ref

$104 \quad 156 \quad 1.71(1.09-2.69)$

$37 \quad 95 \quad$ Ref

$130 \quad 228 \quad 1.19(0.56-2.52)$

1123 Ref

$2 \quad 10 \quad 0.34(0.07-1.57)$

$10 \quad 23 \quad 0.74(0.34-1.59)$

129218 Ref
Table 5 (continued)

\begin{tabular}{|c|c|c|c|}
\hline \multirow[t]{2}{*}{ Variables } & \multicolumn{2}{|c|}{$\begin{array}{l}\text { Refusal of } \\
\text { vaccination }\end{array}$} & \multirow[t]{2}{*}{$\operatorname{COR}(95 \% \mathrm{Cl})$} \\
\hline & Yes & No & \\
\hline \multicolumn{4}{|l|}{ Profession * } \\
\hline Medical doctor & 15 & 19 & Ref \\
\hline Laboratory technician & 16 & 30 & $0.68(0.27-1.68)$ \\
\hline Nurse and midwive & 32 & 98 & $0.41(0.19-.91)$ \\
\hline Pharmacist & 29 & 21 & $1.75(0.73-4.22)$ \\
\hline Radiographer & 7 & 11 & $0.81(0.25-2.58)$ \\
\hline Anesthesiologist & 10 & 11 & $1.15(0.39-3.43)$ \\
\hline Public health officer & 8 & 28 & $0.36(0.13-1.02)$ \\
\hline Non-medical auxiliary staff & 24 & 33 & $0.92(0.39-2.17)$ \\
\hline \multicolumn{4}{|l|}{$\begin{array}{l}\text { Received training or orientation } \\
\text { about COVID-19 vaccination * }\end{array}$} \\
\hline No & 99 & 136 & $1.99(1.29-3.09)$ \\
\hline Yes & 42 & 115 & Ref \\
\hline \multicolumn{4}{|l|}{$\begin{array}{l}\text { Knowledge level about COVID-19 } \\
\text { vaccine* }^{*}\end{array}$} \\
\hline Poor & 67 & 80 & $1.94(1.27-2.96)$ \\
\hline Good & 74 & 171 & Ref \\
\hline \multicolumn{4}{|c|}{ Attitude towards COVID-19 vaccine* } \\
\hline Negative & 97 & 90 & $3.94(2.54-6.12)$ \\
\hline Positive & 44 & 161 & Ref \\
\hline \multicolumn{4}{|l|}{ Perceptions of COVID-19 vaccine* } \\
\hline Poor & 93 & 62 & $5.91(3.76-9.27)$ \\
\hline Good & 48 & 189 & Ref \\
\hline
\end{tabular}

*Indicates variables included in the multivariable logistic regression analysis; Ref, reference category

tested for COVID-19 were significantly associated with the acceptance of COVID-19 vaccine [34]. In our study, having COVID-19-infected family members, colleagues, or friends was associated with increased vaccine uptake intention only in the bivariate analysis but not in the final adjusted logistic model (Table 5). In addition, as indicated in Table 4, 39.5\% of the HCWs associated vaccines with possible COVID-19 infections and $46.9 \%$ of them thought that vaccines could worsen any pre-existing medical conditions. This is very concerning, as it indicates that HCWs are not convinced about the safety of COVID-19 vaccines and are also misinformed. The reason for this widespread misinformation is not known but the public health agencies in Ethiopia may need to increase their efforts to educate HCWs about the safety of these vaccines.

\section{Limitation of the study}

Bias may have affected the result of our study. Social desirability bias in which HCWs answered questions in a manner that would be viewed favorably by others may have resulted in over-reporting of good attitudes and 
Table 6 Multivariable analysis of factors significantly associated with refusal to be vaccinated for COVID-19 vaccine among healthcare workers in Dessie City, Ethiopia, May 2021

\begin{tabular}{|c|c|c|c|c|c|}
\hline \multirow[t]{2}{*}{ Variables } & \multicolumn{2}{|c|}{ Refusal of vaccinations } & \multirow[t]{2}{*}{ COR $(95 \% \mathrm{Cl})$} & \multirow[t]{2}{*}{ AOR $(95 \% \mathrm{Cl})$} & \multirow{2}{*}{$\begin{array}{l}\text { P-value } \\
\text { (adjusted model) }\end{array}$} \\
\hline & Yes & No & & & \\
\hline \multicolumn{6}{|l|}{ Profession } \\
\hline Medical doctor & 15 & 19 & Ref & Ref & \\
\hline Laboratory technician & 16 & 30 & $0.68(0.27-1.68)$ & $0.98(0.34-2.83)$ & 0.973 \\
\hline Nurse and midwive & 32 & 98 & $0.41(0.19-.91)$ & $0.38(0.15-.97)$ & 0.042 \\
\hline Pharmacist & 29 & 21 & $1.75(0.73-4.22)$ & $1.50(0.53-4.25)$ & 0.445 \\
\hline Radiographer & 7 & 11 & $0.81(0.25-2.58)$ & $0.66(0.16-2.33)$ & 0.470 \\
\hline Anesthesiologist & 10 & 11 & $1.15(0.39-3.43)$ & $0.72(0.20-2.60)$ & 0.617 \\
\hline Public health officer & 8 & 28 & $0.36(0.13-1.02)$ & $0.46(0.14-1.50)$ & 0.197 \\
\hline Non-medical auxiliary staff & 24 & 33 & $0.92(0.39-2.17)$ & $0.97(0.36-2.66)$ & 0.955 \\
\hline \multicolumn{6}{|c|}{ Attitude towards COVID-19 vaccine } \\
\hline Negative & 97 & 90 & $3.94(2.54-6.12)$ & $3.06(1.86-5.03)$ & $<0.001$ \\
\hline Positive & 44 & 161 & Ref & Ref & \\
\hline \multicolumn{6}{|l|}{ Perception of COVID-19 vaccine } \\
\hline Poor & 93 & 62 & $5.91(3.76-9.27)$ & $4.73(2.91-7.68)$ & $<0.001$ \\
\hline Good & 48 & 189 & Ref & Ref & \\
\hline
\end{tabular}

perceptions as well as intended uptake of vaccines. Moreover, causal inferences cannot be drawn from this study due to the nature of the study design.

\section{Conclusion}

The willingness to get vaccinated against COVID-19 was moderately high among healthcare workers in Dessie City. Negative attitudes and poor perceptions of HCWs towards COVID-19 vaccines were the most significant factors in the refusal to accept vaccines. Because HCWs are scheduled to be among the first to receive vaccines and play a central role in their administration in the population, key factors in their decision-making process, such as knowledge about the safety of vaccines, must be addressed as early as possible. Our findings may inform health planners and administrators in developing relevant interventions that promote COVID-19 vaccination uptake among healthcare workers in Ethiopia. In particular, the large proportions of HCWs who considered vaccines to worsen any pre-existing medical conditions or cause COVID-19 is very concerning, as it seems that HCWs are not convinced about the safety of the vaccines and are also misinformed. These issues need to be urgently addressed by the public health agencies in Ethiopia. Working on behavioral change communication and social mobilization towards COVID-19 vaccines using culturally appropriate manner might increase the attitudes and perceptions, which in turn increasing the rate of COVID-19 vaccination. We also recommend studies in urban and rural communities to investigate the religious conspiracy about COVID-19 vaccines that may ensure increasing the vaccination rate of COVID-19.

\section{Implication of the study}

The information on attitudes, knowledge and perceptions pertaining to the refusal of COVID-19 vaccine among HCWs can inform policy makers and administrators about opportunities and constraints in distributing vaccines among HCWs in Dessie and other Ethiopian cites. The findings may thus contribute to developing a strategy for controlling the pandemic by addressing factors significantly affecting vaccination uptake.

\section{Abbreviations}

AOR: adjusted odds ratio; Cl: confidence interval; COR: crude odds ratio; HCWs: healthcare workers.

\section{Acknowledgments}

We gratefully acknowledge Wollo University for providing the ethical clearance letter, which allowed us to do this study. We also express our thanks to Dessie City health bureau for giving permission to conduct this study. We also acknowledge the managers of the public and private healthcare facilities in Dessie City for their permission to conduct this study and for the information we received when needed. We thank the data collectors and supervisors for their assistance and all study participants for their participation and valuable information.

\section{Authors' contributions}

AA and MA conceptualized, designed, analyzed, and interpreted the data, prepared a draft manuscript and edited the manuscript. HK conceptualized, 
designed, and edited the manuscript. AA and MA contributed equally to this work. All authors read and approved the final manuscript.

\section{Funding}

No funding was obtained from institution. However, data collection budget was covered by Dr Helmut Kloos, who is a co-author for this study.

\section{Availability of data and materials}

The datasets analyzed during the current study are available from the corresponding author on reasonable request.

\section{Declarations}

\section{Ethics approval and consent to participate}

Ethical approval was obtained from the Institutional Ethical Review Committee of the College of Medicine and Health Sciences of Wollo University. Informed written consent was obtained from study subjects after explaining the purpose of the study and assurance that their information would not be used for purposes other than scientific research. Confidentiality was ensured by using code numbers rather than names. All the methods used comply with the principles and ethical standards of the declaration of Helsinki.

\section{Consent for publication}

Not applicable

\section{Competing interests}

The authors declare that they have no competing interests.

\section{Author details}

${ }^{1}$ Department of Environmental Health, College of Medicine and Health Sciences, Wollo University, Dessie, Ethiopia. ${ }^{2}$ Department of Epidemiology and Biostatistics, University of California, San Francisco, CA, USA.

Received: 24 July 2021 Accepted: 24 November 2021

Published online: 18 January 2022

\section{References}

1. Worldometer. Coronavirus Cases: deaths: recovered : [Internet]. 2021 [cited 2 Jul 20, 2020], Available from: https://www.worldometers.info/ coronavirus.

2. FDRE (Federal Democratic Repuplic of Ethiopia). COVID-19 state of emergency. Addis Ababa; 2020.

3. BBC. Covid-19 Africa: what is happening with vaccines? Which coun tries are using up [Internet]. 2021. Available from: https://www.bbc. com/news/56100076.

4. Reuters. Ethiopia to get 300, 000 doses of Sinopharm COVID-19 shot, health minister says [Internet]. 2021. Available from: https:// www.reuters.com/article/uk-healthcare-coronavirus-ethiopia-id USKBN2BL1TE.

5. WHO. Ethiopia introduces COVID-19 vaccine in a national launching ceremony [Internet]. 2021. Available from: https://www.afro.who. $\mathrm{int} /$ news/ethiopia-introduces-covid-19-vaccine-national-launchingceremony.

6. African Vaccine Acquisition Trust delivers 108,000 doses of COVID19 vaccine to Ethiopia - Africa CDC [Internet]. 2021. Available from: https://africacdc.org/news-item/african-vaccine-acquisition-trust-deliv ers-108,000-doses-of-covid-19-vaccine-to-ethiopia.

7. Reuters. Ethiopia, COVID-19 tracker [Internet]. 2021 [cited Apr 27, 2021]. Available from: https://graphics.reuters.com/world-coronavirus-trackerand-maps/countries-and-territories/ethiopia.

8. Africanews. NEWS Ethiopia launches Covid vaccination in Addis Ababa. 2021; Available from: https://www.africanews.com/2021/03/14/ethiopialaunches-covid-vaccinations-in-addis-ababa

9. Holder Josh. Covid World Vaccination Tracker - The New York Times [Internet]. The New York Times. 2021. Available from: https://www.nytim es.com/interactive/2021/world/covid-vaccinations-tracker.html.
10. Paul E, Steptoe A, Fancourt D. Attitudes towards vaccines and intention to vaccinate against COVID-19: Implications for public health communications. Lancet Reg Health - Eur. 2021;1:100012.

11. Muhumuza R. vaccine hesitancy adds to slow rollout of doses. Associated Press, Kampala. [Internet]. 2021. Available from: Available at: http:www. wkr.com/news/in-africa-vaccine.

12. Materu B. Tanzanians urged to use traditional medicine for Covid-19 [Internet]. 2021. Available from: https://www.theeastafrican.co.ke/tea/ news/east-africa/tanzania-traditional-medicine-covid-19-3276402.

13. Khadka D, Dhamala MK, Li F, Aryal PC, Magar PR, Bhatta S, et al. The use of medicinal plants to prevent COVID-19 in Nepal. J Ethnobiol Ethnomed. 2021;17(1):1-17.

14. Worku AM. A review on significant of traditional medicinal plants for human use in case of Ethiopia. J Plant Pathol Microbiol. 2019;10(6):1-12.

15. WHO. WHO issues its first emergency use validation for a COVID-19 vaccine and emphasizes need for equitable global access [Internet]. 2020. Available from: https://www.who.int/news/item.

16. Wouters OJ, Shadlen KC, Salcher-Konrad M, Pollard AJ, Larson HJ, Teerawattananon Y, et al. Challenges in ensuring global access to COVID-19 vaccines: production, affordability, allocation, and deployment. Lancet [Internet]. 2021;397(10278):1023-34. https://doi.org/10.1016/S01406736(21)00306-8.

17. Biswas N, Mustapha T, Khubchandani J, Price JH. The nature and extent of COVID-19 vaccination hesitancy in healthcare workers. J Community Health [Internet]. 2021;(0123456789). Available from: http://www.ncbi. nlm.nih.gov/pubmed/33877534.

18. Al-Metwali BZ, Al-Jumaili AA, Al-Alag ZA, Sorofman B. Exploring the acceptance of COVID-19 vaccine among healthcare workers and general population using health belief model. J Eval Clin Pract. 2021(April):1-11.

19. Gadoth A, Halbrook M, Matine-Blais R, Gray A, Tobin NH, Ferbas KG, Adrovandi GM RA. Cross-sectional assessment of COVID-19 vaccine acceptance among healthcare workers in Los Angeles. Ann Internal Med. 2021; Available from: https://doi.org/10.7326/M20-7580.

20. Shekhar R, Sheikh AB, Upadhyay S, Singh M, Kottewar S, Mir H, et al. COVID-19 vaccine acceptance among health care workers in the United States. Vaccines. 2021:9(2):1-18.

21. Agyekum MW, Afrifa-Anane GF, Kyei-Arthur F, Addo B. Acceptability of COVID-19 vaccination among healthcare workers in Ghana. Adv Public Health. 2021. https://doi.org/10.1155/2021/9998176.

22. Kabamba Nzaji M, Kabamba Ngombe L, Ngoie Mwamba G, Banza Ndala DB, Mbidi Miema J, Luhata Lungoyo C, et al. Acceptability of vaccination against COVID-19 among healthcare workers in the Democratic Republic of the Congo. Pragmatic Obs Res. 2020;11:103-9.

23. Fares S, Elmnyer MM, Mohamed SS, Elsayed R. COVID-19 vaccination perception and attitude among healthcare workers in Egypt. J Prim Care Community Health. 2021;12.

24. Paudel S, Palaian S, Subedi N. Risk perception and hesitancy toward COVID-19 vaccination among healthcare workers and staff at a medical college in Nepal. Risk Manag. Health Policy. 2021:2253-61.

25. Tobin EA, Okonofua M, Azeke A, Ajekweneh V, Akpede G. Willingness to acceptance a covid-19 vaccine in nigeria: a population-based cross-sectional study. J Med Res [Internet]. 2021;5(2):1-6. Available from: https:// www.alliedacademies.org/allied-journal-of-medical-research.

26. Qattan AMN, Alshareef N, Alsharqi O, Al Rahahleh N, Chirwa GC, AlHanawi MK. Acceptability of a COVID-19 vaccine among healthcare workers in the Kingdom of Saudi Arabia. Front Med. 2021;8(March):1-12.

27. Chew NWS, Cheong C, Kong G, Phua K, Ngiam JN, Tan BYQ, et al. An Asia-Pacific study on healthcare worker's perception and willingness to receive COVID-19 vaccination. Int J Infect Dis [Internet]. 2021;106:52-60. Available from: http://www.ncbi.nlm.nih.gov/pubmed/33781902

28. Sun Y, Chen X, Cao M, Xiang T, Zhang J, Wang P, et al. Will healthcare workers accept a COVID-19 vaccine when it becomes available? A crosssectional study in China. Front Public Health. 2021;9(May):1-8.

29. Huynh G, Tran TT, Nguyen HTN, Pham LA. COVID-19 vaccination intention among healthcare workers in Vietnam. Asian Pac J Trop Med. 2021:14(4):159-64.

30. Singhania N, Kathiravan S, Pannu AK. Acceptance of coronavirus disease 2019 vaccine among health-care personnel in India: a cross-sectional survey during the initial phase of vaccination. Clin Microbiol Infect [Internet] 2021;2019-21. Available from: https://doi.org/10.1016/j.cmi.2021.03.008. 
31. Alle YF, Oumer KE. Attitude and associated factors of COVID-19 vaccine acceptance among health professionals in Debre Tabor Comprehensive Specialized Hospital, North Central Ethiopia; 2021: cross-sectional study. Virus Disease [Internet]. 2021; Available from: https://doi.org/10.1007/ s13337-021-00708-0,

32. Ciardi F, Menon V, Jensen JL, Shariff M a, Pillai A, Venugopal U, et al. knowledge, attitudes and perceptions of COVID-19 vaccination among healthcare workers of an inner-city hospital in New York. Vaccines. 2021;9(5):516.

33. Elhadi M, Alsoufi A, Alhadi A, Hmeida A, Alshareea E, Dokali M, et al. Knowledge, attitude, and acceptance of healthcare workers and the public regarding the COVID-19 vaccine: a cross- sectional study. BMC Public Health. 2021;1-21.

34. Mesele M. COVID-19 Vaccination acceptance and its associated factors in Sodo Town, Wolaita Zone, Southern Ethiopia: cross-sectional study. Infect Drug Resist. 2021;2361-7.

\section{Publisher's Note}

Springer Nature remains neutral with regard to jurisdictional claims in published maps and institutional affiliations.

- fast, convenient online submission

- thorough peer review by experienced researchers in your field

- rapid publication on acceptance

- support for research data, including large and complex data types

- gold Open Access which fosters wider collaboration and increased citations

- maximum visibility for your research: over $100 \mathrm{M}$ website views per year

At BMC, research is always in progress.

Learn more biomedcentral.com/submissions 